Hofmann, E. (2005):

Supply Chain Finance: some conceptual insights.

In: Lasch, R./ Janker, C.G. (Hrsg.): Logistik Management - Innovative Logistikkonzepte, Wiesbaden 2005, S. 203-214.

Dr. Erik Hofmann

Kühne-Institut für Logistik (KLOG-HSG)

Universität St.Gallen

Dufourstrasse 40a

CH-9000 St.Gallen 


\title{
Supply Chain Finance - some conceptual insights
}

\author{
Dr. Erik Hofmann \\ Kuehne-Institute for Logistics, University of St.Gallen, Switzerland \\ erik.hofmann@unisg.ch; Phone: +41 (0)71 224 72 95; www.klog.unisg.ch
}

\begin{abstract}
The flow of financial resources in supply chains is increasingly drawing the centre of attention. Even the task of supply chain managers begins with the financing and capital budgeting decisions of value creation relevant investments and ends only after the payment from the customer is received. As a consequence new tasks at the intersection of finance and logistics/supply chain management open new business areas for banks as well as financial and logistics service providers. This paper can be understood as a first step enabling executives to look behind the Supply Chain Finance (SCF) approach.
\end{abstract}

\section{$1 \quad$ Introduction}

While the integration of material and information flows within the supply chain has been discussed and tested in practice, the flow of financial resources is increasingly taking centre stage of attention (Pfohl/Hofmann/Elbert (2003)). There seems to be the need to address more economical and financial problems as logistics consider not only the flow of goods and related information. Supply chain management should also bear in mind cash flows as well as the implications of the financial side of business activities. The challenges arising with these developments bring along a new understanding and role of the supply chain actors and their relationships. New inter-functional and interorganizational tasks at the intersection of finance and logistics open new supply chain opportunities.

But do logisticians and supply chain manager understand and speak the financial language of the board members? Do they know all the internal and external financial challenges to guide the economic output of supply chain activities? Do they have a profound understanding of all the levers laying in use of financing components in the supply chain context? Did they already begin to build up cross-functional competences to surmount the firm-specific and interorganisational silos between the operational and the financial side? 
Supply Chain Finance (SCF) is an approach that focuses upon theses questions from a collaborative viewpoint. The following discussion is based on the conceptual ground of logistics/supply chain management and the finance theory. By studying the relevant literature, this paper aims to provide the reader some insights into Supply Chain Finance. After covering the basics and relevant aspects of the surrounding management fields, the reader will be prepared to follow the definition and characterization of Supply Chain Finance. The institutional, supply chain, and functional analyses look beyond the definitional surface and provide an in-depth coverage of the relevant elements. To round up the theoretical elucidations, this paper closes with illustrative examples.

\section{Characterization and constituent elements of Supply Chain Finance}

While the research areas of logistics, supply chain management, collaboration, and finance have been discussed throughout the years, Supply Chain Finance is considered a relatively young discipline. Exhibit 1 illustrates the Supply Chain Finance approach for an organization and its tier one supply chain environment, including potential service providers. As indicated at the bottom of the figure, the collaboration is ideally extended also to cover the tier two supply chain members and if it is required finally the whole supply chain. The financial and operating activities of an organization are closely connected and interdependent. Collaborating in the upper half ("financial side") or in the lower half of the arrow ("operating side") therefore only represents a sub-optimization, potentially forgoing benefits that can be reaped from an encompassing collaboration approach. Consequently, we should keep in mind that even though collaboration focuses on financial functions, institutions, and instruments of supply chains only, it should not be understood as an isolated concept but rather as an aspect of a more complex system. To reduce some of the complexity of this system, a company will choose to integrate and manage different supply chain links for different business processes, meaning it will collaborate on all areas with some supply chain members, while only collaborating financially, operatively, or not at all with others (Timme/Williams-Timme (2000)).

As also can be seen in the figure, a financial services or logistics services provider is not a genuine member of a supply chain. He only get involved by providing services for one of the supply chain members. Thereby Supply Chain Finance is more than just collaborations between the finance departments of two or more companies. Instead, SCF is marked by the focus on financial aspects or the usage of financial instruments, which might apply to any department of an organization. Note that the categorization whether a financial collaboration is 
established or not, is determined in the functional dimension while the criteria whether we are talking about a "plain" cooperation or supply chain collaboration is determined institutionally. For example, collaborations between an industrial company and a financial service provider are always a financial collaboration since the financial service provider offers financial support or knowledge. So, we only speak about SCF if the relationship is focused on the supply chain objects, considering all flows, processes, current and fixed assets, as well as personnel that are involved in the supply chain (Timme/WilliamsTimme (2000), p. 33).

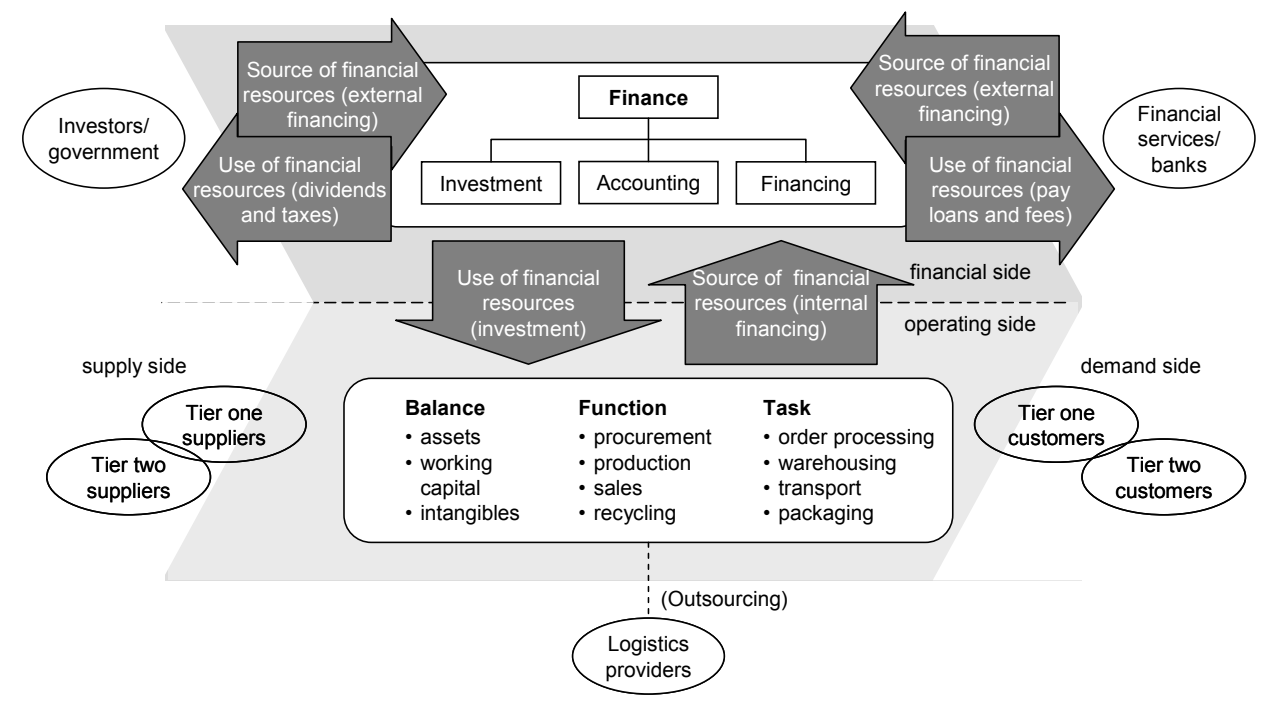

Exhibit 1: The Supply Chain Finance approach.

In line with the characterization presented here, a working definition of Supply Chain Finance can finally be put as follows: Located at the intersection of logistics, supply chain management, collaboration, and finance, Supply Chain Finance is an approach for two or more organizations in a supply chain, including external service providers, to jointly create value through means of planning, steering, and controlling the flow of financial resources on an interorganizational level. While preserving their legal and economical independence, the collaboration partners are committed to share the relational resources, capabilities, information, and risk on a medium- to long-term contractual basis. The instrumental contribution of SCF is based on three constitutive elements: (1) institutional actors, (2) supply chain management characteristics, and (3) financial functions. These elements, which can be understood as a framework of 
Supply Chain Finance, are taken into account, while making value chain decisions in a financial way.

\section{$3 \quad$ Institutional actors in Supply Chain Finance}

An institutional perspective is looking at the different participants of Supply Chain Finance. This includes not only the different companies taking part in the collaboration, but also their organizational subdivisions and units. The macroand micro-institutional actors resulting from this distinction will be discussed individually. The separation has to be taken into account because of the various understandings and accesses to financial flows and instruments in supply chain environments.

\subsection{Macro-institutional actors}

The macro institutions within SCF are defined as legally and economically independent units. A financial perspective on the supply chain requires an extension of the "traditional" supply chain institutions. We will first present the traditional actors and have a look at these new institutions afterwards.

The minimal supply chain imaginable is between an industrial or commercial company, also called shipper or sender, and its supplier and costumer. The supplier can be identified by the fact that his materials, goods, or services are needed for the shipper's production process. While industrial companies produce materials and goods, commercial companies are concerned with gathering and distributing these in the direction of the ultimate customer. Their customer can either be another commercial or industrial company or the final consumer (Gibbs (1998)). This way, many supplier-customer relationships may exist before the product or service reaches the final customer.

Logistics service providers (LSP) are an additional institution that might be involved in the supply chain. They are not considered genuine members of a supply chain though and only by offering services for one or more original supply chain members they get involved. Traditionally being concerned with the transportation and storing of materials and goods between the customer and supplier, the logistics services industry is currently undergoing a considerable change and the scope of services is largely extended. Since companies are increasingly concentrating on their core competences, the value-added and administrative services provided by logistics services, like payment or aftersales services, are getting even more important (Maloni/Benton (1997)).

In a financial supply chain context, the group of supply chain actors must be extended by financial institutions, namely special financial services, banks, and investors. In a narrow sense, financial services providers are all institutions 
whose business is dedicated to balancing other institutions' investment and financing needs. In a wider sense, financial services comprises all institutions aiming at the conclusion of financial contracts between original and/or intermediate lenders and borrowers or merely enabling them, without being a contracting party. This definition covers services like financing services, capital investment at banks or insurances, securities investments or risk coverage. Information and consulting services, as provided for example by rating agencies or M\&A-consultants, are also included in this wider understanding of financial services (Hines/Hurtt/Langsam (2000)).

Investors can be distinguished into public and private investors. Public institutions offer several programs supporting raise equity. The different existing groups of private investors can generally be broken down into capital investors, e.g. real estate investors, and financial investors, e.g. venture capital companies (Pfohl/Hofmann/Elbert (2003), p. 6).

\subsection{Micro-institutional actors}

As presented above macro-institutional actors of the supply chain have different organizational and process structures. As a result, the relevant microinstitutional units involved in the operating and financial processes of a supply chain may be found in different organizational settings. Not only the internal but also a company's external intersection with other supply chain members might therefore be varying. In a common understanding of supply chain management, the micro-institutional actors comprise all departments involved with the operational activities (e.g. purchasing, production, distribution and logistics units). In a financial supply chain context, all departments dealing with financial activities are now included as well (Pfohl/Hofmann/Elbert (2003), p. 6). While making investment, accounting, and financing decisions, the accounting, the controlling, and the finance departments have to taken into account.

When looking at micro-institutional actors the main concern is solving intersection problems, which are the right allocation of tasks and responsibilities. The question is which department at which hierarchy-level is best entrusted with the decisions and tasks originating from the financial supply chain process. The flow of financial resources builds the intersection of the operating and the finance side. Supply chain management aims at optimizing this flow as well as the flow of goods and material, information, and rights throughout the whole value creation process, which is from the point of origin to the point of consumption. Hence, the "financial" supply chain is concerned with managing the financial functions induced by the logistics processes within the considered supply chain echelons. Supply Chain Finance is an approach that tries to put this idea into actions by coordinating the participants' joint activities. 


\section{Collaboration characteristics in Supply Chain Finance}

The typical finance activities are designed for single businesses or their subunits. An application of these tasks in a supply chain environment requires a modification to consider inter-organizational aspects. The adaptations needed to design a supply chain-wide performance system are superimposed by the influences focused on covering the special aspects of Supply Chain Finance.

Next to the indirect effects of supply chain performance indicators on financial goals of a firm, the direct payments between the FSC-members have to be considered. This is necessary because the supply chain collaboration is shaped by contractual regulations not only concerning the quantity and delivery times of goods or services, but also the prices and payment policy (Holten/Schultz (2001), p. 579). The financial flows within a collaboration of supply chainactors are determined by strategic decisions taken in a formed cooperation. Contractual agreements about the payment conditions put these strategic decisions into action. The tracking and controlling of payments is therefore an essential part of supply chain collaboration's day-to-day business.

Further more in supply chain collaborations, there is no longer a homogenous group of investors. Instead, shareholders of the different members have individual preferences of risk and return. In other words, the specific discount rates of the different collaboration entities have to be taken into account. The collaborating companies remain legally independent entities ultimately only responsible for delivering value to their own investors. The advantage to go ahead with Supply Chain Finance will therefore have to be proven individually for each single member. To determine whether a participation in the collaboration is advantageous, each entity will consider the cash inflows and outflows that are expected. These consist of cash outflows associated with creating the necessary organizational and technical prerequisites, the cash inflows and outflows associated with the day-to-day processes, and the potential excess cash inflows reaped from the collaboration. The incentive sought to align the collaboration's overall and each member's individual goals can be provided by transfer payments between the entities. Ideally, these transfer payments are based on objectively measurable criteria. Otherwise the participants will not be induced to reveal the true numbers, in order to receive higher transfer payments.

Two essentially different approaches to create such a system on basis the of shareholder value are conceivable: A direct or bottom-up approach, measuring the supply chain-related data for each collaboration member in a first step and combining it to a "supply chain shareholder value" in a second step, and an indirect or ceteris-paribus approach, deriving the shareholder value added by the supply chain collaboration on basis of each company's overall shareholder 
value. An important assumption for both approaches is the creation of standards. Only widely accepted standards allow the comparability of results.

\section{Functional perspective on Supply Chain Finance}

The functions at the intersection of finance and logistics/supply chain management are investment, financing, and accounting on the finance side and the functions procurement, production, and sales on the operating side. In a collaborative supply chain environment one party's procurement side is usually at least one other party's sales side. Consecutively examining procurement, production, and sales might therefore be confusing. Hence, we prefer to point out special aspects of the mentioned financial functions in a SCF-environment. Note that we are talking about collaborative supply chain functions and not about individual organization's functions. There is an interesting insight attached to this seemingly small difference: Strictly speaking, our understanding of external and internal financing has shifted when looking at finance from a collaborative viewpoint. Traditionally, the inflow of financial resources from outsiders into a company is considered external financing. Here, the inflow of funds from a collaboration partner is not considered external, since we look at the collaboration as to be one entity. Only organizations outside this collaborative entity provide external financing. On a first glance, this point of view seems to stand in contradiction to conventional wisdom. But in fact, the institutions and instruments of external financing have not changed. Only the alternatives for internal financing have broadened within the context of Supply Chain Finance.

\subsection{Tracking financial flows and resources}

The shift from competitive to collaborative strategies require a re-examination of accounting governance systems which were designed for hierarchical modes of governance combined with make-or-buy decisions which assume arms-length transactions (Gietzman (1996), p. 613). In a SCF-environment, accounting is responsible for the identification, measuring and communication of all relevant processes and states within the collaboration. Traditionally, efficiency, which is the ratio of the supply chains' value output to its input (cost), is at the centre of attention for measuring performance. In the collaborative context, additional logistics performance measures such as delivery time, out-of-stock-rate, or delivery flexibility play an important role. For the financial realm, profitability and liquidity, probably the two most commonly used financial measures, certainly have to be taken into account too. But apart from providing these widely used basic measures, the task of tracking financial information in the context of SCF is more complex. The flow of financial resources between the 
respective supply chain members is at the heart of the approach. Accounting therefore has to be capable of tracking these flow figures. The accurate measurement of financial flows - or cash-basis accounting - between collaborating supply chain actors is the basis for identifying internal financing sources. Redirecting these flows to the locations where they can most efficiently be employed is also only possible if accounting can keep track of them. To identify, measure, and communicate the real cash flow figures of an organization, the payments have to be captured at their point of origin. A derivative approach, based on the static balance sheet and the income statement, is not able to comprehensively reflect the cash flow within a given period. This is because even if the bottom-line calculated cash flow is the same, a derivative approach does not show the sources and uses of cash and their time of occurrence. It also cannot reveal the reason of the transaction. But that is exactly what is needed in order to improve a collaborative cash flow management (Hofmann/Elbert (2004), p. 107).

Another aspect is the financial visibility within the collaboration and the availability of information at all times. Static accounting approaches prepare information at periodically recurring points in time, for example in a quarterly, half-yearly or yearly manner. Derivative approaches to calculate cash flows are tied to these points in time. Cash flow calculations based on payment figures on the other hand are continuously available. Especially when looking at ways to accelerate cash flow between two network entities in order to create value, timely information is imperative (Cooper/Lambert/Pagh (1997)).

Many companies focus on static performance measurement tools which do not require a genuine tracking of cash flow figures. Switching costs from the performance-driven to a cash flow-driven accounting system are generally believed to be extensive, since not only IT-systems will have to be changed but also extra information is needed to be recorded. Several approaches exist attempting to calculate cash flow figures on the basis of the commonly used systems by using side calculation, implicitly assuming that a genuine cash flow based system is too troublesome to introduce.

Setting up the right accounting system - that is the right mix between accrualbasis and cash-basis accounting capturing the flow of financial resources between the collaborating actors - can be considered a basic enabler to put Supply Chain Finance successfully into practice. This means involved supply chain actors have to keep track of all payment transactions that occur within the considered value creation echelon. If this payment-based accounting system is used in the context of supply chains only or as part of a company-wide accounting system, is up to each company. It is also well imaginable that the collaboration members set up a central accounting system responsible for 
capturing all financial information. If a suitable accounting system is not set up, all parties will have to rely on unsuitable information, potentially forgoing improvement opportunities and causing conflict and distrust.

\subsection{Using financial resources}

Collaborative investments can occur in all logistics functions and throughout all logistics subsystems, order processing, stock keeping, packing and transportation, hence offering a wide spectrum of investment reasons. When deciding about different investment alternatives, there are two main points to consider: The cash outlay for the investment and the value obtained from the investment. While the cash outlay is comparatively easy to measure, the value connected to the investment has two dimensions: a monetary and a nonmonetary (Brealey/Myers (2000)). Consider for example investments in supply chain-wide information and communication systems. It is hard to attach a quantifiable cash inflow to these kinds of investments. Still, there is undeniably a high value connected to them. Investing in its logistics functions and processes is a task that every single organization is faced with. What is so special about investment in a collaborative supply chain environment then? There are two special aspects to take into account, each of them illustrated by a short case (Baiman/Rajan (2002), p. 213).

First, investments in supply chain collaborations mean that the participants jointly invest in objects that would otherwise be outside their individual organization's scope of consideration. The number of investment alternatives therefore increases. Consider a manufacturing company: In order to enhance its procurement processes, this company from an individual point of view might have the choice of investing in a new warehouse or its incoming goods processes. A financial collaboration with the company's most important supplier offers a new investment alternative: Jointly investing in the supplier's distribution warehouse might potentially enhance the organization's procurement process even more.

Second, the best investment alternative now is the one delivering the highest value to all collaborating parties. This entails considering the cash flows of all participants when deciding about different alternatives. For example, a supplier is going to choose between two order-tracking systems, A and B, where A is the financially more attractive alternative. But when collaboratively looking at the two systems, it turns out that his customer and collaboration partner uses a system similar to B, allowing a link between the two partners and saving considerable administrative costs at the customer's side. The collaborative approach therefore reveals B to be the better investment. In order to align the 
individual and collaborative best choice, an incentive cash transfer system will have to be established between the collaborating parties (Carr/Tomkins (1996)).

The opportunities of collaborative investment activities (e.g. incremental capital expenditure), collaborative debt management, and ways to collaboratively influence the costs of capital (WACC), represent areas for further improvement that could only superficially be scratched here and need more thorough coverage in subsequent studies.

\subsection{Sourcing financial resources}

Procurement, production, sales, and recycling can potentially free up internal financing resources. But not only investments in these functions, also goods and services between supply chain members and service providers have to be paid for and therefore need financing. Finally, investors, the government, special financial service providers, and banks provide external financing. At the same time they have financial claims towards the collaborating supply chain members, whether it is the payment of dividends, taxes and fees, or the payback of loans. Assuming that equity financing only plays a minor role within the context of supply chains, debt financing and internal financing are the two areas we need to focus upon.

Debt financing can be broken down into long-term borrowing, short-term borrowing, and credit substitutes. The debt financing opportunities of a company are mainly influenced by the company's credit rating, the securities, and the willingness of the lender. According to these factors, SCF leads to an improvement of the possibilities for the involved parties on the capital and money markets because of concentrated knowledge and capital. SCF therefore improves the debt financing alternatives and conditions for all collaboration partners. Special attention should be given to commercial credit, which traditionally represents a form of short-term borrowing. The commercial credit policy of the involved parties directly influences the cash-to-cash-cycles within the supply chains. This promises a high potential of freeing extra cash that is otherwise tied-up in non-value-creating processes, especially when considering that commercial credits are among the most expensive instruments in the range of financial products. A cash discount in Germany for example is usually about $3 \%$ if paid within 20 days. This is equal to a per year interest rate of $54 \%$. Credit substitutes, the third pillar of debt financing, also offer new opportunities when seen from a collaborative supply chain perspective. Several scenarios, especially when including a financial services and/or logistics services provider, for innovatively using factoring or leasing to increase financial performance of a supply chain collaboration are imaginable. 
As we have already seen the commonly used financing alternatives carry another meaning when used in a SCF-environment. The reason for this shift in our understanding is not only due to the new perspective that we take on financing - most conventional finance literature is concerned with individual companies while we look at a network of companies collaborating across traditional financial boundaries - but also because of an essential characteristics of the SCF-approach: the flow orientation. Apparently, the conventional categorization of internal financing alternatives is static, denoting that it originates from end-of-the-year balance sheet identities. This means that on the balance sheet, the internal financing balance is identical to the sum of selffinancing sources, financing from retained earnings, financing from depreciation, and financing from redeployment of capital. When taking a flow perspective, these categories do not exist, since they have no cash payments associated. Sources of financing are only those that represent a direct inflow of cash. Or put in another way: Accounting earnings are not cash, since they cannot be spent. Notice that depreciation is able to generate cash by the realization of tax savings.

\section{Conclusion: illustrative examples}

To further illustrate the meanings of Supply Chain Finance, this paper concludes with two examples.

The first example deals with two companies representing consecutive supply chain echelons who are undertaking a collaborative investment in a logistics asset. This asset could be a warehouse or distribution centre between the two partners in order to enhance and accelerate their supply chain processes. The collaborative investment decision is concerned with choosing the alternative containing the highest value for both parties. Apart from the expected operations performance of such an investment, which symbolizes the logistics aspect of the decision, the financial aspect is equally important. For each possible investment alternative, the collaborating partners need to specify: What is the amount and timely distribution of cash outflows for the investment? How are these cash outflows shared between the two partners? What are the expected savings as opposed to the current situation and how are these savings distributed? Collaboratively established decision criteria will help to choose one of the viable alternatives. Once the investment decision is made, the question of financing arises. Collaboratively, the SCF-partners have more financing options than each individual company does alone.

As the second case we want to look at Supply Chain Finance containing a financial services provider. A good example is when two consecutive supply 
chain members collaborate with a bank in order to improve their cash management. This option is especially attractive when assuming that the supply chain members are located in different countries, since international bank transactions are usually costly and associated with considerably high administrative effort. Collaborating with a bank can therefore result in savings for the companies. One way to achieve this is the creation of so-called lockbox accounts for the supply chain members. A lockbox is a bank-maintained account into which a company's customers directly send payments while the bank processes the checks received and deposits the payments directly into the company's accounts. This separation of the cash handling duties and cash record-keeping duties improves the companies' internal controlling and accelerates cash collection. Transfers between the supply chain members' lockboxes can occur at comparatively low cost and may include extra valueadded services. The services provided by the bank might reach even further and contain debtor and/or creditor management facing other suppliers and customers. The resulting pooling of cash, the improved timing in cash disbursements and receipts, and the better controlling can lead to significant value-added for the members of the collaboration.

Many of the financial elements presented in this paper comprise the employment of an external service provider. Due to the novelty of the SCFapproach, the market for service providers offering this type of services is still in its infancy. Logistics and financial service providers are increasingly trying to adapt to the changing requirements though. How successfully collaborative financial processes can be outsourced will primarily depend on how far companies are prepared and willing to open up large parts of their financial system. Given the findings of this paper, it seems justified to predict an increasing importance and dissemination of Supply Chain Finance in the future.

\section{References}

Baiman S., Rajan M.V. (2002): Incentive issues in inter-firm relationships, in: Accounting, Organizations and Society 27 (2002) 3, pp. 213-238.

Brealey, R.A., Myers, S.C. (2000): Principles of Corporate Finance, $6^{\text {th }}$ ed., Boston et al.

Carr, C., Tomkins, C. (1996): Strategic investment decisions: The importance of SCM. A comparative analysis of 51 case studies in U.K, U.S. and German companies, in: Management Accounting Research 7 (1996) 2, pp.199-217. 
Cooper, M.C., Lambert, D.M., Pagh, J.D. (1997): Supply Chain Management. More Than a New Name for Logistics, in: International Journal of Logistics Management 8 (1997) 1, pp. 1-14.

Gibbs, J.E. (1998): Effective Relationships for Supply - Attributes and Definitions, in: European Journal of Purchasing and Supply Management 4 (1998) 1, pp. 43-50.

Gietzmann, M.B. (1996): Incomplete Contracts and the Make-or-Buy Decision: Governance design and Attainable Flexibility, in: Accounting, Organizations and Society 21 (1996) 6, pp. 611-626.

Hines, C., Hurtt, D.N., Langsam, S.A. (2000): Shopping for Cash Management Services, in: The Journal of Corporate Accounting \& Finance. n.v. (2000) November/December, pp. 15-19.

Hofmann, E., Elbert, R. (2004): Collaborative Cash Flow Management Financial Supply Chain Management als Herausforderung der Netzkompetenz, in: Pfohl, H.-Chr. (Ed.): Netzkompetenz in Supply Chains - Grundlagen und Umsetzung, Wiesbaden, pp. 93-117.

Holten, R., Schultz, M.B. (2001): Integriertes Controlling für Aufbau, Betrieb und Anpassung von Supply Chains, in: Wirtschaftsinformatik 43 (2001) 6, pp. 579-588.

Maloni, M.J., Benton, W.C. (1997): Supply Chain Partnerships. Opportunities for Operations Research, in: European Journal of Operational Research 101 (1997) 3, pp. 419-429.

Pfohl, H.-Chr., Hofmann, E., Elbert, R. (2003): Financial Supply Chain Management - Neue Herausforderungen für die Finanz- und Logistikwelt, in: Logistik Management 5 (2003) 4, pp. 10-26.

Timme, S., Williams-Timme, C. (2000): The financial-SCM connection, in: Supply Chain Management Review 4 (2002) 2, pp. 33-40. 